\title{
A Review on Smart Walker for Antalgic and Ataxic Gait Population
}

\author{
Gokul $\mathbf{M}^{1}$, Nithyaa A. $\mathbf{N}^{2}$ \\ Post Graduate Scholar in Medical Electronics, BME Dept., Rajalakshmi Engineering College, Chennai, India ${ }^{1}$
}

Assistant Professor (SG), BME Dept., Rajalakshmi Engineering College, Chennai, India ${ }^{2}$

\begin{abstract}
In the last decade, the clinical reasoning in physical therapy has been to develop smart and automated systems for physiotherapists to make clinical decisions rapidly and efficiently in response to the complex upcoming needs of health and rehabilitation units. The major problem addressed in this review paper is about antalgic and ataxic gait population. The common problem faced by both subjects is improper body weight balance during walking. This imbalance causes them an additional pain in their shoulders and joints, which may lead to serious suffocation. So designing an automated smart walker with balance management system, fall management system and light assistance system can prevent their unnecessary pain and correct their gait pattern too. Along with this walker therapy, Dynamic EMG will be acquired from the subject and transmitted to the concern physiotherapist. Based on the therapy environment, Bluetooth setup is used to transmit the EMG data from patient to the therapist for continuous and periodic assessment of muscle re-education.
\end{abstract}

Keywords: Physiotherapy, antalgic gait, ataxic gait, walker and EMG

\section{INTRODUCTION}

Physiotherapy is the field science, which will cure, prevent and re-educate the muscles, joints and bones of physically disabled and challenged people. The major problem focused on this study is about abnormal gait patterns, specifically antalgic and ataxic gait patterns are taken for this study [1]. According to centres for disease control and prevention (CDC) statistics, From 2013-2015, 54.4 million US adults (22.7\%) annually had ever been diagnosed by arthritis, rheumatoid arthritis, gout, lupus, or fibromyalgia (antalgic gait based disorders). About 1 in 323 children has been identified with Cerebral Palsy (ataxic gait based disorder) according to estimates from CDC's Autism and Developmental Disabilities Monitoring (ADDM) Network. Antalgic gait (Fig. 1) is form of abnormal gait where the swing phase is larger than a stance phase. It caused due to car accident, rheumatoid arthritis, osteoarthritis, gout, etc [1], $[2]$.
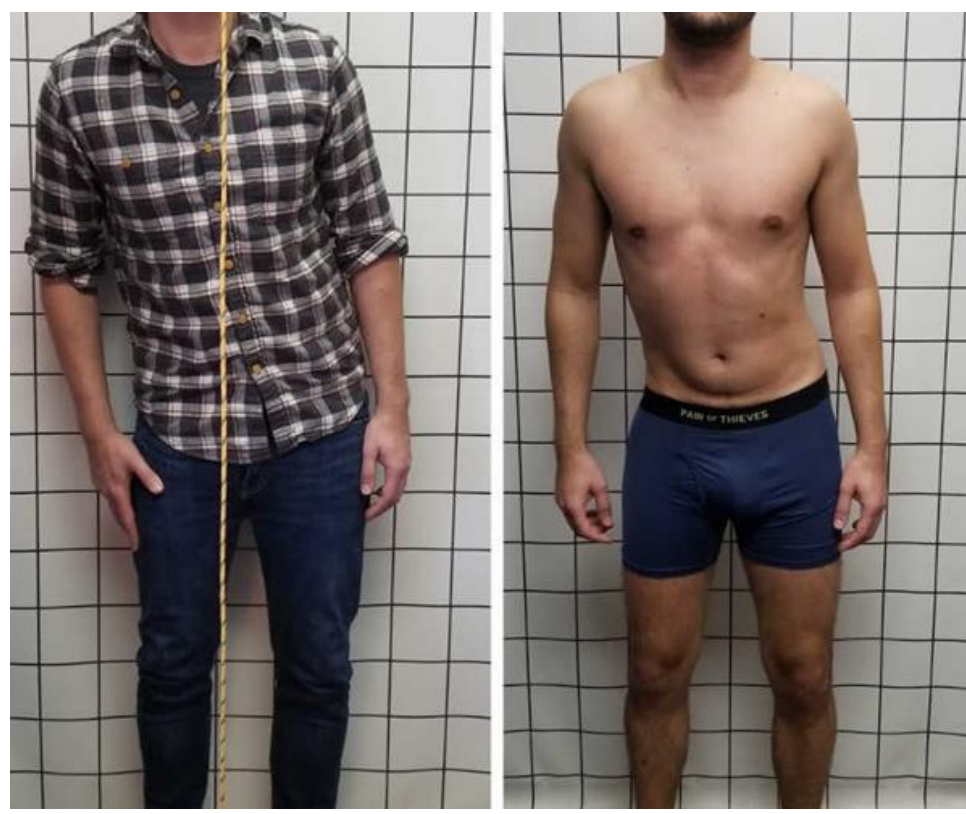

Fig. 1: Subject with antalgic posture and gait with severe spasms along his left erector spinae muscles [3] 


\section{International Journal of Advanced Research in Computer and Communication Engineering}

Vol. 9, Issue 11, November 2020

DOI 10.17148/IJARCCE.2020.91114

Ataxic gait (Fig. 2) is also an abnormal gait where the muscle coordination for walking is poor. It is caused due to stroke, cerebral palsy, head trauma etc $[1,2]$. The existing solution for these abnormal gait patterns are medications (anti-inflammatory drugs) and Hospitalized physical therapy. The major side effects of medications are constipation, nausea, and stomach ulcers. The physical therapy involves exercise and usage of walkers, where walkers are important devices, which will show better result in rehabilitation process [2]. In existing walker method, due to some improper weight balance of patients, additional pain will occur in their shoulders and joints continuously. It may lead to severe and chronic suffocation for patients. In order to prevent those additional pain and to correct the gait pattern, this review paper presents an efficient method, which is the smart walker system. It will continuously monitor the force delivered by the subjects at the walker handle bar, to find the improper balance and it will deliver the haptic feedback to subject when the force exceeding the fixed threshold.

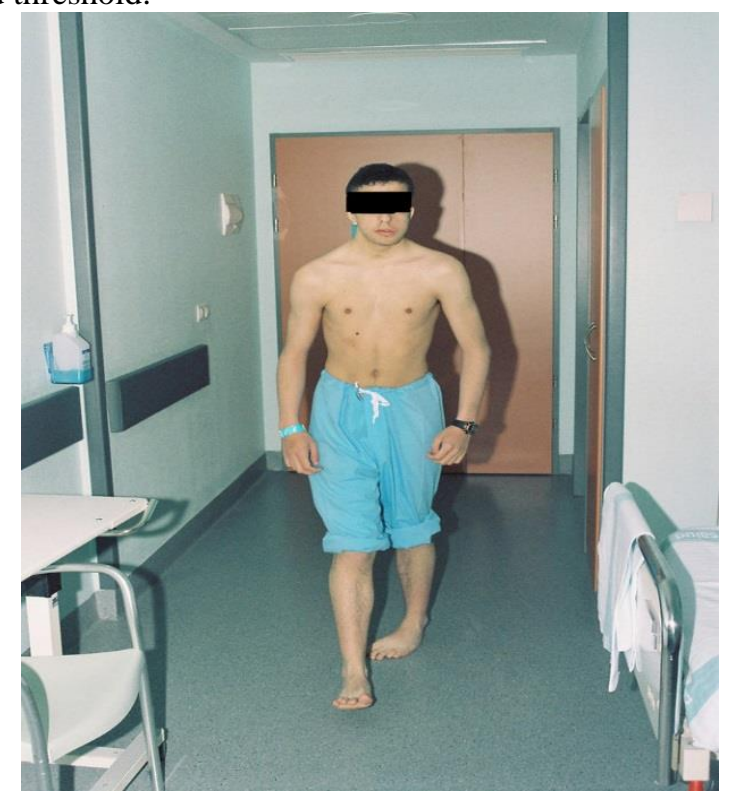

Fig. 2: Dystonia Subject with Ataxic Gait [4]

It automated process will help the patient to take the corrective measure and will assist in maintaining the balanced walk [2]. In addition to this feature, the walker also having automated fall detection feature, which will detect the fall of walker by sensing its acceleration and it will provide an audio output as an emergency sign for help. To avoid the inconvenience in evening and late evening walking, the walker will provide automated light assistance based on the environment light intensity. Along with these features, dynamic Electromyogram (EMG) of the subject will be monitored through the wireless Bluetooth setup for the assessment of muscle re-education. This review paper concentrates on the methods, features and parameter acquisitions of existing research works for assessing the drawbacks. This paper will also review the typical parameter range and choice of sensors for proposed system by analysing its methodology.

\section{REVIEW ON EXISTING WALKERS}

With the help of base of support, subject's centre of mass is maintained and it will maintain the static equilibrium state. When the balance with the base support is altered or displaced, it will automatically affect the body's center of mass. So these action can be prevented when the subjected is provided with walker to maintain the even base of support [5]. Now the addressed problem is about imbalance force distribution for specific gait population. So, let's see the existing walker's types and its functionalities to add customized features in proposed walkers. Generally walker are classified into two major types such as conventional and smart walkers.

\section{A. Conventional Walkers}

Based on the support towards the ground, conventional walker is classified into standard, front wheeled and rollators [6]. The Standard walker is the simple walker which doesn't require any criteria like maximum weight requirement in subject's upper portion of the body and it is very much easier than crutches and cane (Fig. 3(a)) [7]. In this walker also having drawback like back fall of subject while holding the walker itself [8]. But this drawback doesn't matter for our targeted population because, mostly back fall was occurred for Parkinson patients [8]. The problem which we are addressing is about improper balance. It is between left and right side of the body. 


\title{
International Journal of Advanced Research in Computer and Communication Engineering
}

\author{
Vol. 9, Issue 11, November 2020
}

\section{DOI 10.17148/IJARCCE.2020.91114}

Front wheeled walkers (Fig. 3(b)) are designed and suggested for patient who couldn't lift and move the standard walker. It will also be suggested for Parkinson patients to prevent the back fall as mentioned by cubo et. al. by analysing the freezing phase of the subjects [9]. In our case, incorporation of wheel feature will be difficult, because our targeted population's walking speed is slow, so they couldn't pick up the speed of front wheel walker [10].

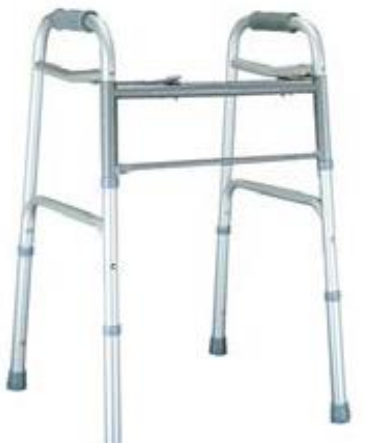

(a)

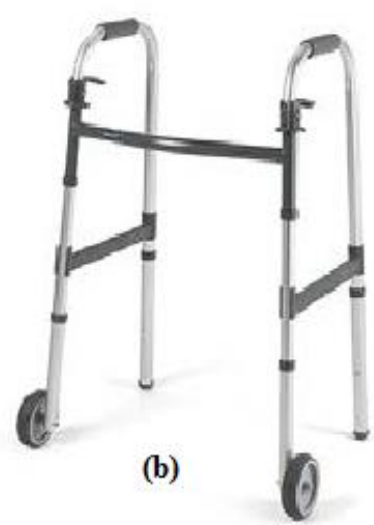

(b)

Fig. 3: a) Standard walker [6] b) Front wheeled walkers [6]

Rollator is an advanced and easiest walker among the three conventional walker as per studies [8]. It is equipped with wheels for smooth movement with very less effort and it also having seating facility, which is an add-on feature for subjects to take rest in between the walk [7]. Hand brakes are available in the rollator, but we have to educate and train the subject according to its function [10]. The best example for evolved rollators are U step walking stabilizer [11] and Boomer (assistive in climbing stairs) [12]. These two rollators needs subject's input while performing the action, but that is not possible all the time. As per few studies made earlier, 30-50\% percent patient were not using the above mentioned walkers continuously, because of an inconvenience nature [13]. Actually above mentioned device requires continuous attention and control capacity [14] but it may not possible all the time and it will be difficult for patients with excessive dysfunction [8].

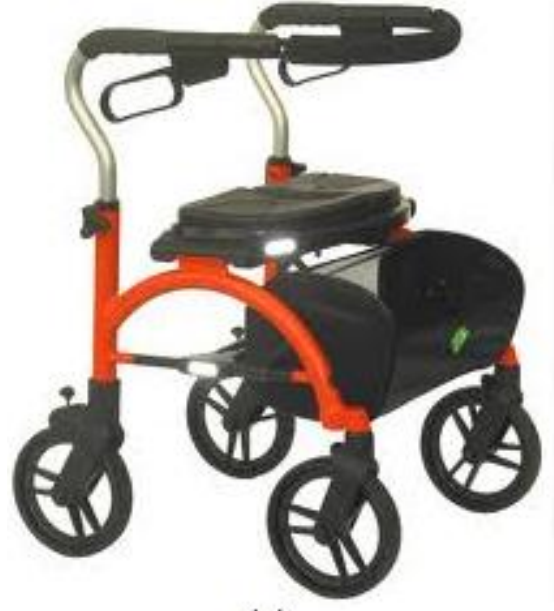

(a)

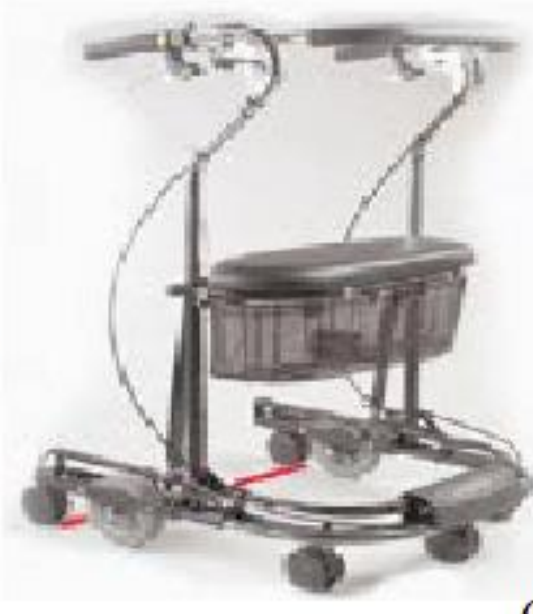

(b)

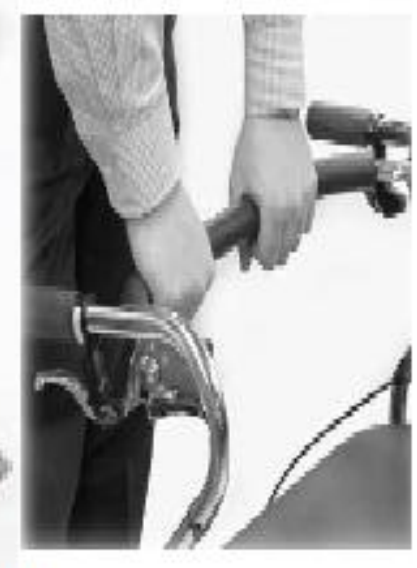

Fig. 4: a) Rollator [8] b) U step walking stabilizer [11]

\section{B. Smart Walkers}

Smart walkers have arisen with similar structure as the ordinary ones yet they incorporate extra mechanical and electronic segments, that elevate a superior help to stride, particularly considering route [15], step checking [16], and halfway body weight uphold [16] [17]. When planning or suggesting a walker, it is expected to consider the subject's handicaps in improper balance management and mobility issues as well as the way that huge numbers of subjects have extra lacks at psychological disabilities or low perception in decision making. For example, geriatric population normally present more delay in decision making and are inexperienced with modernized smart gadgets. So in such cases, walkers should be intended to consistently assess and address their activities dependent on their impression of 


\section{International Journal of Advanced Research in Computer and Communication Engineering}

Vol. 9, Issue 11, November 2020

DOI 10.17148/IJARCCE.2020.91114

the necessities of the subject. Based on the functionalities and features, there are few types of smart walker exists. They are categorized as physical, sensory, cognitive and health monitoring assistance.

Physical assistance smart walkers are mainly designed in the motive to provide complete physical support and stability to the subject. The electronic components are used to provide automated support and it is placed in the lower part of walker to maintain dynamic stability and usual handlebar is replaced by arm rest platform [18] [19]. The drawback of this system is that shape and weight of the walker will be high. For example, ASAS [19], Mobil walker [20] and SIMBIOSIS [21] are smart physical assistance walker, which has forearm rest platform and it has more stability in physical movement which have tested for spine injury patients [19-21]. The problem with these walker is to control the speed of the walker, as mentioned in front wheel walker, it is difficult for geriatric population to use those brake system. In order to overcome that drawback, personal adaptive mobility aid walker is developed [22, 23]. It will automatically control the wheels and movement to the maximum level in practical scenario. Again, it fails to provide balanced force in handlebars.

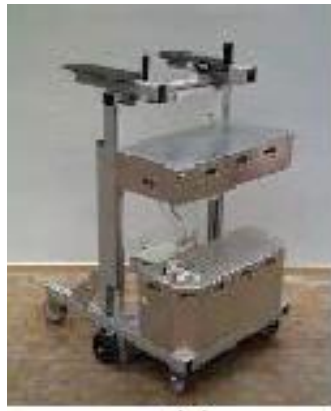

(a)

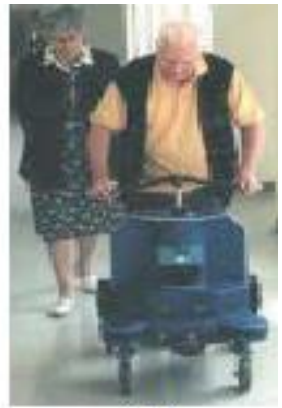

(b)

Fig. 5 a) Mobil Walker [20] b) Personal adaptive mobility aid walker [22]

In sensory assistance smart walker, the sensorial assistance will be given to the subject like navigating or guiding the subject by detecting the huddles in the pathway. Personal adaptive mobility aid walker [22] and MARC smart walker [25] are designed on that basis to detect the obstacles in the pathway. But it can be useful for blind population but our targeted population is not necessary to be blind. In cognitive assistance smart walker, the walker will be programmed to guide the subject from outdoor to respective home. It is specially meant for subjects who have poor memory related problem. For example iWalker [24] is designed on that way to provide navigation maps to subject in order to reach right place. In our case, our subjects will be in clinical environment, so navigation doesn't play major role. PAMM smart walker [26] will come under health monitoring smart walker, which will monitor the heart activity of the patient continuously for dysthymias. But in our proposed walker, we will monitor the muscle activity too for better assessment in muscle reeducation.

In general, there are few drawbacks still exists in smart walker. The notable problem and concern in smart walkers is the brake mechanism that must be effortlessly controlled, instinctive and viable, to evade perilous circumstances, for example, high speeds of the walker on slipping surfaces can cause fall of the subjects [27]. But brake system is not an issue in our walker, because of the absence of wheels. Furthermore, in smart walker it is critical to comprehend and examine the dynamic model of the walker, to measure and improve the solidness of the walker, while the subject is managing it through obscure region. Moreover, it is important to discover parts that are low utilization and the battery framework must be improved [27]. For wellbeing the electrical framework must be segregated from the climate in a nook to keep harm from fluid spills, and so on. On another perspective, the re-charge season of the batteries ought not to be longer than eight hours to accomplish full charge hence the recharge can be at night time [27]. These are the drawbacks and the features to be improved in smart walker. Still the main feature (Automated force balance system) which we are adding in our proposed walker is absent in both conventional smart walker.

\section{III.REVIEW ON PROPOSED WALKER}

As mentioned earlier, proposed smart walker system has four major features. They are automated balance management, fall management, light assistance and Wireless EMG monitoring. This sub-review is to study the typical parameter range for each system and also to study and elaborate the methodology of each system.

\section{A. Balance management system}

The main reason for this system is to provide the balanced walk pattern to the subjects. Because of improper balance, additional pain may occur in rest of the body. This system will continuously monitor the force delivered by the subjects at the walker handle bar, to find the improper balance and it will deliver the haptic feedback to subject when the force 


\section{International Journal of Advanced Research in Computer and Communication Engineering}

Vol. 9, Issue 11, November 2020

DOI 10.17148/IJARCCE.2020.91114

exceeding the fixed threshold. The force can be measured using force sensitive resistor (FSR) [28]. So the typical range force delivered by normal hand should be known. This study was done by Nikonovas et al., as per their research, typical force range for normal subject is ranging from 16 to $25 \mathrm{~N}$ [29]. The range may vary according to object which we are holding, but for basic reference, this could be helpful in initial testing. After sensing the force, if the value exceeds the threshold vibration (haptic feedback) will be provided to the patient for corrective measure. From the work of Allison M. Okamura [30], haptic feedback methodology is inferred and based on their force feedback, vibration is added in our feedback. In order to deliver the precise and typical range of vibration, Jinho Yim et. al [31] work is inferred. As per them, the optimal and typical range of vibration for physiological sensation is from 150 to $180 \mathrm{hz}$. So, this automated process will help the patient to take the corrective measure and will assist in maintaining the balanced walk.

\section{B. Fall management System}

In order to sense and detect the position of walker, fall management system is designed. It will detect the fall of walker by sensing its acceleration and it will provide an audio output to the subject's environment as an emergency sign. The major component in this system is acceleration sensor. So typical range of acceleration for normal walk should be known. As per Davrondzhon Gafurov, et. al [32], acceleration of normal walking is around 1.3g. This range may vary with respect to the speed. So typical range with respect to speed was inferred from D. Satkunskiene et. al [33] study. As per them, when the subject is walking around at the speed of $2-8 \mathrm{~km} / \mathrm{hr}$, then the acceleration would be around 1 to $6 \mathrm{~m} / \mathrm{s} 2$. So these typical ranges can be taken as reference values before taking the actual experimented values.

\section{Light Assistance system}

The role of this system is to avoid the inconvenience in evening and late evening walking. So this integrated system in the walker will provide automated light assistance based on the environment light intensity. The environment light is sensed on Light depended resistor (LDR) [34]. As per few studies made before, defined discrete values are coded in the controller, like 0 is fixed night, 1023 is fixed for morning light and 512 is fixed for evening [34]. We can few more values too, based on the ranges for light intensity in the environment.

\section{Wireless EMG monitoring System}

Electromyogram (EMG) is the graphical representation of muscle movements and its contractions [8]. This wireless EMG system will dynamically record the EMG signal of the subject, while performing the walking therapy. The acquired signal is transferred from the subject's Bluetooth (BT) module to the physiotherapist's BT module. Due to compact size of the therapy environment, BT is used. The average transmission range of BT is around 100 meters [35]. The speed of the Bluetooth signal transmission is around 115200bps [36]. The amplitude range of the acquired signal will be displayed in physiotherapist end. As per Kunju, Nissan, et al, the amplitude range for slow walk is around 0.03 $-0.04 \mathrm{mv}$ and for fast walk is around $0.05-0.06 \mathrm{mv}$. The frequency of walking EMG signal is around $65-74 \mathrm{hz}$ [37]. The EMG is acquired using the sensor which incorporated the signal conditioning unit with it [38]. In future, we can incorporate the various additional signal monitoring with this system like ECG, EEG, EGG [39] etc.

\section{IV.DISCUSSION}

Notwithstanding the great outcomes that the above introduced research works have demonstrated, a few enhancements should be made regarding logical commitments, plan execution, control calculations and mechanical procedures. This prompts new difficulties that must be endure. Overall conventional walker's drawback are fast movement (wheel based walker), back fall of subject and less functionalities incorporation. The notable drawbacks of smart walkers are inefficient brake system, bulky size and high cost. The major difficulty is improper balancing system which is not yet addressed in any existing walkers before. So, the proposed walker will be designed with such feature to balance the force of the subject. This is the preliminary study, which have been completed before the design of walker. The typical and optimal parameters mentioned in the above review will be incorporated in the actual design. The results of proposed walker yet to study in real time environment under the supervision of physiotherapist.

\section{CONCLUSION}

In this review, the existing therapy methods and its drawbacks for antalgic and ataxic gait population were analyzed and studied. The detailed classification of walkers and its advanced models were discussed along with its pros and cons. In general, the proposed walker will add major four features, which is to provide corrective measure action to the subjects for speedy recovery. The force balancing can be done with the help of periodic usage of walker under clinical 


\title{
International Journal of Advanced Research in Computer and Communication Engineering
}

\author{
Vol. 9, Issue 11, November 2020
}

DOI 10.17148/IJARCCE.2020.91114

supervision. This walker will also correct the gait pattern with respect to their therapy duration. The future work of this review paper is to design and test the proposed walker with the targeted population.

\section{REFERENCES}

[1]. Tarulli, Andrew. "Gait disorders." Neurology. Springer, Cham, 2016. 277-283.

[2]. Van Hook, Frederick W., Dale Demonbreun, and Barry D. Weiss. "Ambulatory devices for chronic gait disorders in the elderly." American family physician 67.8 (2003): 1717-1724.

[3]. Uzi chen. "Case Study: Correcting Severe Antalgic Posture \& Gait." Acusport education (2018). https://www.sportsmedicineacupuncture.com/correcting-severe-antalgic-posture/

[4]. Hernando - Quintana, Natalia \& Playán - Usón, Jesús \& Crespo - Burillo, José \& Marín - Cárdenas, Miguel \& Gazulla, José. (2015). Ataxia and focal dystonia in Kallmann syndrome. Clinical Case Reports. 4. 10.1002/ccr3.420.

[5]. Tagawa, Yoshihiko, et al. "Analysis of human abnormal walking using a multi-body model: joint models for abnormal walking and walking aids to reduce compensatory action." Journal of Biomechanics 33.11 (2000): 1405-1414.

[6]. Standard Walker: [http://www.technomedic.ca/]. Acessed in 30 May 2010.

[7]. Costa, Nelson, and Darwin G. Caldwell. "Control of a biomimetic" soft-actuated" 10dof lower body exoskeleton." The First IEEE/RAS-EMBS International Conference on Biomedical Robotics and Biomechatronics, 2006. BioRob 2006.. IEEE, 2006.

[8]. Constantinescu, Radu, et al. "Assistive devices for gait in Parkinson's disease." Parkinsonism \& related disorders 13.3 (2007): 133-138.

[9]. Cubo, Esther, et al. "Wheeled and standard walkers in Parkinson's disease patients with gait freezing." Parkinsonism \& related disorders 10.1 (2003): 9-14.

[10]. Lacey, Gerard, and Kenneth Dawson-Howe. "Evaluation of robot mobility aid for the elderly blind." Proceedings of the Fifth International Symposium on Intelligent Robotic Systems. Vol. 8. 1997.

[11]. U-Step. [http://www.ustep.com/walker.htm]. Acessed in 30 May 2010.

[12]. Molloy, D.. Boomer. [http://student.designawards.com.au/application_detail.jsp?status=6\&applicationID=5541].Acessed in 30 May 2010.

[13]. SCHERE, MJ. "The impact of assistive technology on the lives of people with disabilities." Designing and Using Assistive Technology-The Human Perspective- (1998).

[14]. Bateni H, Maki B: Assistive Devices for Balance and Mobility: Benefits, Demands, and Adverse Consequences. Arch Phys Med Rehabil 2005, 86.

[15]. Morris AC, Donamukkala RR, Kapuria A, Steinfeld A, Matthews J, Dunbar-Jacobs J, Thrun S: A robotic walker that provides guidance. In Proceedings of the 2003 IEEE Conference on Robotics and Automation 2003, 25-30.

[16]. Frizera A, Abellanas A, Ceres R, Pons JL, Raya R: Study and Characterization of Feet Kinematics in Walker Assisted Gait. Revista Iberoamericana de Automatica e Informatica Industrial (RIAI) 2009, 6(4): 74-84.

[17]. Tan R, Wang S, Jiang Y, Ishida K, Nagano M: Adaptive Controller for Motion Control of an Omni-directional Walker. Proceedings of the 2010 IEEE International Conference on Mechatronics and Automation. Xi'an, China, 156-161.

[18]. Frizera A, Ceres R, Pons J.L, Abellanas A, Raya R: The smart walkers as geriatric assistive device. The SIMBIOSIS purpose. Gerontechnology (Valkenswaard) 2008, 7:108-115.

[19]. Ceres R, Pons JL, Calderón L, Mesonero-Romanos D, Jiménez VF, Sánchez X, Abizanda P, Saro B, Bonivardo G: Andador activo para la rehabilitación y el mantenimiento de la movilidad natural. IMSERSO, Estudios I+D+I 2005, 25:1 - 8 .

[20]. Borgolte U: A novel mobility aid for independent daily living of elderly people. In Proceedings 5th European Conference for the Advancement of Assistive Technology (AAATE) 1999, $267-271$.

[21]. Frizera A: Interfaz Multimodal para modelado, estudio y asistencia a la marcha mediante andadores robóticos -Phd Thesis, 2010, Universidad de Alcalá.

[22]. Lacey G, MacNamara S, Dawson-Howe KM: Personal adaptive mobility aid for the infirm and elderly blind. Lecture Notes in Computer Science 1998, 1458:211-220.

[23]. MacNamara S, Lacey G: A smart walker for the frail visually impaired. In Proceedings of IEEE International Conference on Robotics and Automatonomous 2000.

[24]. Cortés U, Martínez-Velasco A, Barrué C, Martín X, Campana F, Annicchiarico R, Caltagirone C: Towards an intelligent service to elders mobility using the i-Walker. Proc. of AAAI Fall Symposia AI in Eldercare: New Solutions to Old Problems 2008, Washington, USA.

[25]. Wasson G, Gunderson J, Graves S: Effective shared control in cooperative mobility aids. In Proceedings of the Fourteenth International Florida Artificial Intelligence Research Society Conference 2001, 1:1-5.

[26]. Dubowsky S, Genot F, Godding S, Kozono H, Skwersky A, Yu H, Yu LS: PAMM - A Robotic Aid to the Elderly for Mobility Assistance and Monitoring. In: IEEE International Conference on Robotics and Automation 2000, San Francisco, 570 -576.

[27]. Martins, Maria M., et al. "Assistive mobility devices focusing on smart walkers: Classification and review." Robotics and Autonomous Systems 60.4 (2012): 548-562.

[28]. Nithyaa A.N, Premkumar.R , Geethaaanandhi C., Gokul M., Manjusha.M. DIABETIC FOOT ULCERATION SCREENING VIA GSM SETUP ALONG WITH FLEXIFORCE SENSORS. JCR. 2020; 7(19): 6071-6077. doi:10.31838/jcr.07.19.702

[29]. Nikonovas, A., et al. "The application of force-sensing resistor sensors for measuring forces developed by the human hand." Proceedings of the Institution of Mechanical Engineers, Part H: Journal of Engineering in Medicine 218.2 (2004): 121-126.

[30]. Okamura, Allison M. "Haptic feedback in robot-assisted minimally invasive surgery." Current opinion in urology 19.1 (2009): 102

[31]. Yim, Jinho, Rohae Myung, and Byongjun Lee. "The mobile phone's optimal vibration frequency in mobile environments." International Conference on Usability and Internationalization. Springer, Berlin, Heidelberg, 2007.

[32]. Gafurov, Davrondzhon, Einar Snekkenes, and Patrick Bours. "Gait authentication and identification using wearable accelerometer sensor." 2007 IEEE workshop on automatic identification advanced technologies. IEEE, 2007.

[33]. Satkunskiene, D., et al. "487. Acceleration based evaluation of the human walking and running parameters." Journal of Vibroengineering 11.3 (2009).

[34]. Rath, Deepak Kumar. "Arduino based: Smart light control system." International Journal of Engineering Research and General Science 4.2 (2016): 784-790.

[35]. Lee, Ukjun, Hyeongyeol Park, and Hyunchol Shin. "Implementation of a bluetooth-LE based wireless ECG/EMG/PPG monitoring circuit and system." Journal of the Institute of Electronics and Information Engineers 51.6 (2014): 261-268.

[36]. Youn, Wonkeun, and Jung Kim. "Development of a compact-size and wireless surface EMG measurement system." 2009 Iccas-Sice. IEEE, 2009. 


\section{International Journal of Advanced Research in Computer and Communication Engineering}

Vol. 9, Issue 11, November 2020

DOI 10.17148/IJARCCE.2020.91114

[37]. Kunju, Nissan, et al. "EMG signal analysis for identifying walking patterns of normal healthy individuals." Indian Journal of Biomechanics 118 (2009).

[38]. M, Gokul, Durgadevi N, and Ram Kumar C. "Capsule Based Gastric Rhythm Analyzer: A Tool for Diagnosing Gastric Diseases.” Journal of Gastrointestinal \& Digestive System 07, no. 06 (2017). doi:10.4172/2161-069x.1000544.

[39]. Gokul, M., et al. "Rehabilitation Tool for Gastroparesis by the Analysis of Interstitial Cells of Cajal (The External Gastric Pacemaker with a Feedback of Gastric Potential)." J Gastrointest Dig Syst 8.557 (2018): 2.

\section{BIOGRAPHY}

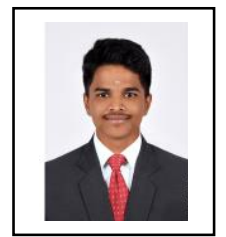

Gokul M. has completed Bachelors in Biomedical Engineering and doing his Masters in Medical Electronics. He also having one and half year biomedical industry working experience. He was one of the finalists in Indian innovation challenge and design contest - 2016, which was conducted by Texas instruments, US and IIMB, India. He also received 5, 00,000 INR as a seed fund for his prototype development. His research interests are Biomedical Instrumentation, bio-signal processing and rehabilitation engineering.

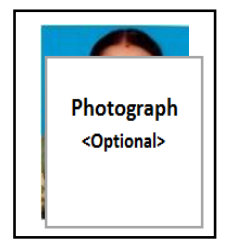

Nithyaa A N. has completed Bachelors in Electrical and Electronics Engineering and done Masters in Biomedical Engineering. She is also doing her Doctorate in Rehabilitation Engineering under Anna University. Currently, she is working as an Assistant professor (SG) with a working experience of 13 years. She have published many research and review articles under the research interest of Biomedical instrumentation, Medical image processing, Bio-signal processing and rehabilitation Engineering. 